\title{
Assistance to high-risk newborns: from the hospital to their homes
}

\author{
Assistência a recém-nascidos de alto risco: do hospital ao domicílio
}

Elaine Trevezanuto Correia ${ }^{1}$, Dandara Novakowski Spigolon ${ }^{1}$, Edilaine Maran ${ }^{1}$, Maria Antonia Ramos Costa ${ }^{1}$, Sonia Silva Marcon², Elen Ferraz Teston ${ }^{3}$

Objective: to apprehend the perceptions of caregivers of high-risk newborns about care provided by health professionals. Methods: a qualitative study with 11 main caregivers of newborns. Data were collected through semi-structured interview, audio recorded, and submitted to content analysis. Results: caregivers of high-risk newborns emphasized the reception at birth and information on the health and evolution of the baby during hospitalization and at discharge, as factors that made the difference in the hospital setting. In the context of Primary Care, those that reflected on the safety/trust and satisfaction with the assistance provided were: multi professional care, follow up with the pediatrician in the reference center, home visit and nursing consultation. Conclusion: caregivers of high-risk newborns perceived positively the care provided by health professionals, both in the hospital environment and at home.

Descriptors: Infant, Newborn; Primary Health Care; Child Care; Nursing; Caregivers.

Objetivo: apreender percepções de cuidadoras de recém-nascidos de alto risco sobre assistência prestada por profissionais de saúde. Métodos: estudo qualitativo, com 11 cuidadoras principais de recém-nascidos. Dados coletados por meio de entrevista semiestruturada, audiogravada, e submetidasà análise de conteúdo. Resultados: as cuidadoras dos recém-nascidos de alto risco destacaram o acolhimento por ocasião do nascimento e as informações sobre as condições de saúde e evolução do bebê durante a internação e no momento da alta, como fatores que fizeram a diferença no âmbito hospitalar. No contexto da Atenção Primária, os que refletiram na segurança/confiança e satisfação com a assistência prestada foram: atenção multiprofissional, acompanhamento com o pediatra no centro de referência, visita domiciliar e consulta de enfermagem. Conclusão: as cuidadoras dos recém-nascidos de alto risco perceberam positivamente a assistência prestada pelos profissionais da saúde, tanto no ambiente hospitalar quanto no domicílio.

Descritores: Recém-Nascido; Atenção Primária à Saúde; Cuidado da Criança; Enfermagem; Cuidadores.

\footnotetext{
${ }^{1}$ Universidade Estadual do Paraná. Paranavaí, PR, Brazil.

${ }^{2}$ Universidade Estadual de Maringá. Maringá, PR, Brazil.

${ }^{3}$ Universidade Federal de Mato Grosso do Sul. Campo Grande, MS, Brazil. 


\section{Introduction}

The Health Care Networks were created in Brazil with the purpose of organizing health services, due to the complexity of the health-disease process, the occurrence of multiple determinants and incoherence among the current causes of morbidity and mortali$\operatorname{ty}^{(1)}$.

Among the Priority Health Care Networks, we highlight the Rede Cegonha (Stork Network), whose objective is the implementation of a network of care for reproductive planning, prenatal care, delivery and puerperium, in order to guarantee humanized and qualified care for women and babies. One of the components of this network is the risk stratification of the child at birth, which is intended to contribute to safe growth and development. In this way, the organization of the points of the network and the frequency of care can ensure attention to the real needs and prevent risks and harms early ${ }^{(1-2)}$.

In this sense, risks are stratified into three categories: habitual, intermediate and high risk. The latter is considered in the presence of factors such as prematurity, severe asphyxia (Apgar less than 7 in the fifth minute of life), low birth weight, severe malnutrition, inadequate intrauterine growth and/or development, presence of positive neonatal screening ${ }^{(2)}$.

It should be noted that gestation is one of the most striking periods in the life cycle of women, most often characterized by positive feelings and uncertainties. The mother is positively prepared to receive the baby at the probable date of delivery that is referred to her on the first day of prenatal care, plans to wait for a full-term, uninterrupted ${ }^{(3-4)}$ neonate. In this way, when the baby has some risk factor, it causes discomfort to the family in the face of the unknown, who, for the most part, feel unprepared and vulnerable to errors $^{(4)}$. Fear and difficulty in dealing with a situation different from what is expected reflect on the emotional security of the mother and other relatives, which results in the need for reception and support by health professionals ${ }^{(2,4)}$.

In this regard, the family, especially the primary caregiver of the high-risk newborn, may present fragility due to unpreparedness in relation to basic care with the baby. The situation is exacerbated by a lack of understanding of the progression of prognosis and the care needed during the child's growth and development ${ }^{(3)}$.

In this context, an important strategy is the set of guidelines offered to family members, especially the primary caregiver of the child regarding the care and need for home care by the Family Health Strategy team ${ }^{(5)}$. Nursing plays a fundamental role in health education during the hospital discharge process of the newborn at risk, when informing, deciding the parents' doubts ${ }^{(4)}$ and counter referring the neonate to Primary Care, in order to facilitate the return home.

However, in the literature, there is a scarcity of approach regarding the continuous multi professional care, between primary and tertiary care, to the high-risk newborn, especially regarding the counter reference and interaction of the health team in the organization and planning this assistance. Thus, it is essential for the health sector to propose multidisciplinary actions that promote measures and strategies that facilitate interaction between the different points in the care network and ensure the well-being of these newborns ${ }^{(6)}$.

In addition, when considering the recent implantation of the Paraná Mother Network and the relevance of its purpose, it is believed that it is necessary to know the users' perceptions regarding the operationalization, as this may contribute to the improvement of care provided to high-risk infants in different points provided in this network, as well as providing subsidies for the implementation of similar services in other scenarios. In view of the above, the objective was to understand the perceptions of caregivers of high risk newborns about the care provided by health professionals. 


\section{Methods}

A qualitative study carried out in a medium-sized municipality, located in the northwestern region of Paraná, Brazil, which has approximately 81,590 inhabitants and is home to one of the 22 Health Regions of Paraná, which includes 20 municipalities.

In the area of child health, at the time of the study, it had 17 Basic Health Units, all with Family Health Strategy teams (total 24 teams), County Emergency Service, a private hospital contracted to the Unified Health System, Regional Center of Specialties, Integrated Health Care System, Mobile Care Unit, Child Psychosocial Care Center, Medical Care Unit.

The choice of the Basic Health Units was intentional, considering the two with the highest number of records of newborns stratified as high risk. To collect data, the nurses of the respective units were asked to authorize, without interfering with the service schedule, to accompany the Community Health Agents in home visits to the puerperal women, so that the invitation to participate in the study and explanation of the type of participation desired were made personally. The inclusion of the participants was convenient, considering the order of completion of home visits by the Community Health Agents. Forty-two newborns met the eligibility criteria of the study, four caregivers were not located in three visits performed on different days and times and 11 were invited to participate in the study, which they accepted. It is reported that new inclusions occurred until additional information ceased to appear and data became repetitive in addition to the purpose of the study being achieved.

In order to select the participants, the inclusion criteria were adopted: being 18 years of age or older, being the primary caregiver of a child born in the period from January to March 2018, stratified at birth as being at high risk and the child not being hospitalized at the time of data collection. At the same time, exclusion criteria were defined as: migrant caregivers residing in Brazil for less than a year, due to the difficulty of communication and interpretation of language. It is pointed out that there was no exclusion.

The data were collected from August to September of 2018, through an audio-video interview, with an average duration of 25 minutes, using a script prepared by the researchers, consisting of two parts, the first one related to the identification information of the main caretaker (current age, need for hospitalization at birth and duration of the disease, risk-defining motive, number of child-care consultations to date), evaluation of the child's vaccination status the vaccination card and the completion of the growth and development chart). The second part was composed of the following questions: talk about the care provided by health professionals to the baby from birth to the moment. How do you qualify for this assistance? Why?

The interviews were transcribed in their entirety by the main researcher, preferably on the same day they were carried out, and submitted to content analysis, thematic modality, following the steps of pre-analysis, material exploration, results survey and interpretation $^{(7)}$. In the pre-analysis, the lectures were read and the key points were surveyed, according to the proposed objective, these being: guidelines received, multi professional assistance, different strategies used in follow-up. Subsequently, the data were coded, originating the following core: factors that influence satisfaction and confidence in the care of high-risk children; and finally, the categorization, by means of the junction between the elements that resemble, giving rise to two thematic categories: In-hospital care: from birth to discharge and primary care health care.

The ethical precepts of research with human beings were respected and the project was approved by Ethics Committee, according to opinion $\mathrm{n}^{-}$ $2,798,410$. The interviewees signed the Free and Informed Consent Term, in order to guarantee their anonymity, in the presentation of the results, the narrative strata are identified by the letter $\mathrm{C}$, indicative of caretaker, followed by the Arabic number referring to the order of interview and risk factor of the newborn. Example: (C1, prematurity). 


\section{Results}

During the study period, 42 newborns were stratified as high risk. Eleven primary caregivers, aged between 20 and 52 years, participated in the study, with only one not being the mother of the child, but the maternal grandmother.

The 11 newborns were less than six months old and eight were males, with an average birth weight of $2.198 \mathrm{~kg}$ (minimum of $0.750 \mathrm{~kg}$ and maximum of $3.490 \mathrm{~kg}$ ). The predominant risk factors were low birth weight (in eight of them) and prematurity (in seven of them). Eight of them required hospitalization at the Intensive Care Unit at birth, with an average of 24 days (minimum of two and maximum of 73 days) of hospitalization.

In the first three months of life, infants spent an average of four childcare consultations, but the health chart of seven children did not have a completed growth and development chart and five children were late in the vaccination schedule.

The primary caregivers of high-risk newborns have learned to confront the loss of the idealized child and to care for the day-to-day of a much more fragile being than expected. In the midst of this, it was found that some specific situations and a differentiated attention to the child or even to the caregiver greatly influenced the way they perceived the care directed to the children, while providing satisfaction and confidence.

\section{In-hospital care: from birth to discharge}

It was observed that the care offered by the professionals in the hospital environment, through the reception, contributed to the satisfaction and confidence of most caregivers: She was in the intensive care unit, the nurse gave me a book on premature babies because she looked very desperate when I was going to visit the baby, a book that talked about everything that is going to happen, everything that they will go through; they have a book and gave it to me to read; helped a lot because we are better prepared to feel safe (C11, Prematurity/Low weight). I got tired of getting there at the intensive care unit and seeing them (different professionals) rocking the baby, the day my son was disengaged, the nurse was crying with me ... these things are making us trust... these things were me reassuring (C3, Prematurity).

Effective communication between the professionals and the caregiver, with guidance on the details of the baby's evolution, was also referred to as a source of safety: I was all the time oriented about what was happening to him... It was all very much well explained, everything about what was happening, what could happen (C6, Prematurity/Cleft Palate/Pierre Robin syndrome).

They also pointed out that the guidelines offered at the time of hospital discharge emerge as an aegis foundation for continuity of family care and follow-up of the baby at home: I was told that he would have consultation with the pediatrician, because it is high risk and also every month in the post with the staff there... and vaccination also guided me to go in the post... explained everything right (C2, Prematurity/Low weight). The doctor at the time of leaving the hospital passed several guidelines on care... she said that my baby was premature and even going home, it was still premature. The first 30 days mainly I had to stay with her at home, she should not be leaving, receiving many visits, because she could get something... influenza (C4, Prematurity). At the time of discharge from the hospital, I was advised that it was to get him to vaccinate and also in the post office consultations that this would help me see if he was growing up the right way (C9, Congenital Syphilis). All the professionals are very attentive, came to guide me where I had to go, why I had to go, because I was going, that this monitoring was very important to observe if he would be losing weight... I was well oriented... I have nothing to complain about since their birth until I left the hospital (C8, Low weight).

Given the difficulties experienced in the breastfeeding process, the caregivers emphasized the assistance provided by the hospital staff as an important source of support: The instructions I had at the hospital raised many doubts of mine. My other son I nursed only up to three months and I started to bottle because I thought my milk was not supporting him, because in the breast he was pregnant all the time and I did not understand it and people talk too much. Then, this time, with your care, the guidelines and help were all different (C7, Prematurity/Low weight/Congenital foot). How careful they were there in the hospital! They stayed up all the time asking why he had lost weight, they would go in the room every hour to ask if he was sucking, because he wanted to get only one chest in the other not because he was without a nipple, hence he cried of hunger because at Sometimes, he did not want to nurse and then they would go there and help (C5, Low weight). 


\section{Health Care in Primary Care}

The care, support and follow-up performed by different primary care professionals were also highlighted by caregivers as a positive aspect in this assistance: The care my baby received, made and makes a lot of difference because they have many places that do not have the care that he had ... he has had enough consultants in these three months, was looked by general practitioners, pediatricians, nurses (C1, Prematurity)....if my baby and I had not received the care as it was, I was lost, I would not know what to do ....they help, they talk what they have to do and how to do it, they guide it right, they follow up and that makes the difference (C2, Prematurity/Low weight). I needed out-of-town care for my baby, they took care of everything, we went immediately, we talked to the regional health department, and the other day, we had an appointment if we wanted to go to Curitiba ...everything was fast and we had excellent care (C6, Prematurity/Cleft palate/Pierre Robin syndrome).

Many caregivers made reference to the nursing consultation carried out in Primary Care, highlighting details that, according to them, conferred quality to care: The care in the post was very good. In the old days, it was not the same now, I had never seen taking all the baby's clothes to weigh and examine if it were not for the pediatrician. This time, the nurse did everything, took all the baby's clothes to weigh, made tests on his foot, on the hand, even on the skin of the penis, she told me how to clean it (C5, Low weight). The nurses at the post are always attentive, and when we are discharged, the same week or even the same day comes home, examines the baby, helps to clean the navel correctly and already brings the consultation with the doctor scheduled. The nurse saw that he was yellow too and that's how I got to the doctor in time, who sent me to the hospital to do the light bath (C11, Prematurity/Low weight). The nurse at the follow-up appointment noticed that when he puts him on his feet, his foot is to one side and the other to the other side, I had noticed this before, but I was told it was normal because he was very young. But now, when she was three months old, when she went back to the nurse, she realized that she was going to go to the doctor again, and then I took the records to the regional center (C1, Prematurity).

The home visit by the multi disciplinary team was also highlighted as a tool that facilitates the assistance: $I$ received a visit from the staff of the center, they guided me, the dentist also came who told me about cleaning the baby's gums after the feedings and as they grow, always follow with dentist for teeth to be born and grow strong. They explained to me several things (C3, Prematurity). She was very skinny and almost did not breastfeed and the post team helped me a lot in this part, came here, taught me right as I should. Now, she only wants the breast, left the bottle and even though not having much milk, still prefers the breast to the bottle (C10, Low weight).

The follow-up of the baby by the pediatrician at the reference center for high-risk infants after hospital discharge was mentioned by caregivers as a decisive care for healthy growth and development of the children: Having this consultation with a pediatrician again after discharge is very important because he is an expert and if he is risky, he has to have ... The pediatrician soon realized that he was yellow, I already managed to do the exam the same day and took it back to it (C2, Prematurity/Low weight). The pediatrician who took care of him soon after he was born was the same one he attended after he left the hospital ... so she already knew the baby and that is very important. She advised me about weight, what if she lost more (C3, Prematurity). He was taken care of by the pediatrician, made me feel at ease, he already knows his story ... she said he was getting little weight, made several calculations, grams a day, and asked me to come back next week so she could follow up until he gained more weight ... Then, she released to go every thirty days (C8, Low weight).

\section{Discussion}

As a limitation of this research, it is pointed out that it was carried out in two Basic Health Units belonging to the same programmatic area and, therefore, with a great possibility of including people with the same profile and socioeconomic characteristics, which may have limited the perception of gaps in care provided at different points in the health care network.

In any case, the results obtained allowed to identify the care actions/activities most valued by the caregivers, by arousing them confidence in the care provided and safety for continuity of care at home.

The first category denoted the feeling of acceptance by the health team, providing support and information related to the baby's condition and future evolution of the baby. At the time of discharge, the guidelines received regarding the necessary care in daily life and the monitoring of growth and development by health professionals were highlighted. These actions, carried out in a hospital setting, provided satisfaction and safety to caregivers, which corroborates the re- 
sults of a study carried out at the University Hospital of Minas Gerais, Brazil, in which parents of newborns reported feeling motivated to care, support which they received from the nursing team during hospitalization ${ }^{(8)}$. A study carried out in Colombia also evidenced the positive performance of the nursing team involving the family members in the care process to the newborn, which favored integral, humanized and safe care $^{(9)}$.

Awareness of the actual health condition of the newborn and the early involvement of caregivers in care can strengthen the bond. A study conducted in the United States of America investigated some attributes of the baby and family during the stay in the Neonatal Intensive Care Unit and found that, by improving the early interactions between the family and the baby and the information supply, child, or family during early childhood, which, in turn, favored the development of safe attachment, improved cognitive skills, self-regulation, and emotional and social development of the child ${ }^{(10)}$.

Some difficulties experienced in the daily routine, such as breastfeeding, were circumvented with the help of the health team. A study carried out with eight nurses in a city in Bahia, Brazil, found that in the perspective of these, an important strategy for the healthy growth and development of the baby is the incentive to exclusive breastfeeding, in the different points of attention and in different moments: prenatal, postpartum and home visit, since mothers may have many doubts and difficulties due to the period of adaptation to lactation ${ }^{(11)}$.

In turn, a study carried out in Chile concluded that the period of greatest vulnerability related to breastfeeding is in the first weeks postpartum. In this sense, the importance of preventing the failure of breastfeeding with early support was stressed, before discharge from the maternity ward. It was pointed out as primary factors to support individualized and welcoming care, with time for active listening and development of effective communication ${ }^{(12)}$.

The safety sense of the primary caregiver of the risk newborn is enhanced by being welcomed by the network during the transition from the hospital to the home/primary care. Therefore, a study carried out in a hospital in Curitiba, Brazil, showed the importance of referral and counter-referral in the continuation of care provided to patients and signaled the need to systematize the discharge plan. The same study pointed to the relevance of follow-up care favored by direct communication between hospital care and primary care, and the positive impact in the prevention of recurrent hospitalizations ${ }^{(13)}$. In this sense, the organization of the network services favors the operationalization of systematized assistance and that meets the health/care demands, according to the identified risk stratum.

It is emphasized that the management of care, especially to children stratified as high risk, should be organized in order to guarantee a service network that provides a comprehensive approach to the health-disease process, aiming at health promotion and early onset of follow-up ${ }^{(14)}$. Thus, it contributes to the assistance offered by Primary Health Care, which seeks to keep vigilant to the different needs that arise in the post-discharge period, in order to help the caregivers to circumvent them, since they change constantly.

In this context, the home visit, in the first few days after discharge, is very important for the reception of the new family member, because the family often feels unprepared and full of doubts about returning home. During the visit, guidelines, demonstrations and follow-up of care can be carried out and questions regarding basic care with the child can be answered. In addition, the recognition of sociodemographic conditions and factors that directly influence the health-disease process of the child and the adequacy of the care guidelines to the lived reality are encouraged $^{(15)}$.

As recommended by the Rede Cegonha (Stork Network), a home visit is essential in the first days of the newborn's life, since the orientation towards breastfeeding, caring for the baby, the emotional condition of the puerperal woman, difficulties with regard 
to care, housing, social conditions are identified at the moment, which enables the team to intervene in the best possible way, promoting users' quality of life ${ }^{(2)}$.

In the meantime, a study carried out in Iran pointed to puerperal home care as a tool of great importance in the prevention of complications, especially by the early identification of needs, doubts, as well as an opportunity to promote mother's health and the concep $\mathrm{t}^{(16)}$. Similarly, a study carried out in Maranhão, Brazil, concluded that the home visit was effective in the early identification of postpartum complications and changes in the newborn, such as jaundice ${ }^{(15)}$. It is emphasized that the high-risk condition often makes the puerperal fragile in the first days at home, requiring the assistance of the nursing team to perform the care with the baby, as well as providing an opportunity for guidance on the importance of follow-up concerning growth and development throughout childhood.

In turn, special emphasis was given by caregivers to the nursing consultation, both in the Unit and at home. It is observed in the literature the importance of this for the follow-up of the child's growth and development, especially for early interventions in response to identified needs ${ }^{(17-18)}$. However, gaps were identified in the follow-up of these children, since incomplete completion of the growth and development chart was observed in some children's charts and delayed vaccination schedule. It is reiterated that the nursing consultation is an opportunity for health education, with a focus on health promotion and disease prevention, as well as strengthening the bond and acceptance of the mother-child binomial ${ }^{(19)}$.

A study carried out in Ghana highlighted the importance of strategies that favor the adhesion of caregivers to child care, so that they can follow the changes in the child's growth and development and associate weight and height changes with the general state of health. He added that this adhesion enables professionals to identify problems early in the child's growth and development, increase vaccine coverage, and provide opportunities for health education ${ }^{(20)}$.

\section{Conclusion}

The care provided by health professionals to high-risk newborns in the hospital setting and after discharge was positively perceived by caregivers. The reception and communication with the team during hospitalization and multi professional assistance interfered in this perception; the link with the team, the nursing consultation and the home visit, in the context of Primary Health Care.

\section{Acknowledgments}

To the Municipal Health Department that authorized the research.

\section{Collaborations}

Correia ET and Teston EF collaborated in designing, analyzing and interpreting the data, writing the article and critically reviewing the intellectual content and approving the final version to be published. Spigolon DN, Maran E, Costa MAR and Marcon SS contributed with relevant critical revision of the intellectual content and final approval of the version to be published.

\section{References}

1. Lapão LV, Arcêncio RA, Popolin MP, Rodrigues LBB. The role of Primary Healthcare in the coordination of Health Care Networks in Rio de Janeiro, Brazil, and Lisbon region, Portugal. Ciênc Saúde Coletiva. 2017; 22(3):713-23. doi: https:// doi.org/10.1590/1413-81232017223.33532016

2. Ministério da saúde (BR). Informações de saúde. Institui, no âmbito do Sistema Único de Saúde - SUS - a Rede Cegonha. Brasília: Ministério da Saúde; 2011.

3. Mohammadi E, Nourizadeh R, Simbar M, Rohana $\mathrm{N}$. Iranian women's experiences of dealing with the complexities of an unplanned pregnancy: a qualitative study. Midwifery. 2018; 62:81-85. doi:https://doi.org/10.1016/j.midw.2018.03.023 
4. Van der Waerden J, Galéra C, SaurelCubizolles MJ, Sutter-Dallay AL, Melchior M. Predictors of persistent maternal depression trajectories in early childhood: results from the EDEN mother-child cohort study in France. Psychol Med. 2015; 45(9):1999-2012. doi: dx.doi. org/10.1017/S003329171500015X

5. Wenjuan W, Rathavuth H. Levels and determinants of continuum of care for maternal and newborn health in Cambodia-evidence from a populationbased survey. BMC Pregnancy Childbirth. 2015; 15:62. doi: 10.1186/s12884-015-0497-0

6. Araújo MAN, Lunardi Filho WD, Silveira RS, Souza JC, Barlem ELD, Teixeira NS. Segurança do paciente na visão de enfermeiros: uma questão multiprofissional. Enferm Foco. 2017; 8(1):52-6. doi: https://doi. org/10.21675/2357-707X.2017.v8.n1.984

7. Bardin L. Análise de conteúdo. São Paulo: Edições 70; 2016.

8. Silva PLN, Barbosa SL, Rocha RG, Nunes $T$. Experience and needs of parents from premature neonates hospitalized in a neonatal intensive care unit. Rev Enferm UFPI [Internet]. 2018 [citado 2019 Jan. 13]; 7(1):15-9. Disponível em: http:// www.ojs.ufpi.br/index.php/reufpi/article/ view/6667

9. Jaramillo L, Osorio S, Salazar D. Quality of nursing care: perception of parents of newborns hospitalized in neonatal units. Invest Educ Enferm. 2018; 36(10):e08. doi: dx.doi.org/10.17533/ udea.iee.v36n1e08

10. Gerstein ED, Poehlmann-Tynan J, Clark R. Motherchild interactions in the NICU: relevance and implications for later parenting. J Pediatr Psychol. 2015; 40(1):33-44. doi: dx.doi.org/10.1093/ jpepsy/jsu064

11. Dias RB, Boery RNSO, Vilela ABA. Knowledge of nurses and incentive strategies for family participation in breastfeeding. Ciênc Saúde Coletiva. 2016; 21(8):2527-36. doi: http://dx.doi. org/10.1590/1413-81232015218.08942015

12. Lucchini RC, Márquez DF, Rivera MMS. I want to breastfeed my baby: Unvealing the experiences of women who lived process difficulties in their breastfeeding. Rev Chil Pediatr. 2017; 88(5):622-8. doi: dx.doi.org/10.4067/S037041062017000500008
13. Ribas EN, Bernadinho E, Larrocca LM, Poli Neto P, Aued GK, Silva CPC. Nurse liaison: a strategy for counter-referral. Rev Bras Enferm. 2018; 71(suppl.1):546-53. doi: http://dx.doi. org/10.1590/0034-7167-2017-0490

14. Lucena DBA, Guedes ATA, Cruz TMAV, Santos NCCB, Collet N, Reichert APS. First week of integral health for the newborn: nursing actions of the Family Health Strategy. Rev Gaúcha Enferm. 2018; 39:e2017-0068. doi: http://dx.doi. org/10.1590/1983-1447.2018.2017-0068

15. Medeiros LS, Costa ACM. Postpartum period: the importance of home visits given by the nurse in Primary Health Care. Rev Rene. 2016; 17(1):1129.doi:http://dx.doi.org/10.15253/21756783.2016000100015

16. Milani HS, Amiri P, Mohseny M, Abadi A, Vaziri SM, Vejdani M. Postpartum home care and its effects on mothers' health: A clinical trial. J Res Med Sci. 2017; 16(22):96. doi: dx.doi.org/10.4103/jrms. JRMS_319_17

17. Rocha GM, Cordeiro RC. Assistência domiciliar puerperal de enfermagem na estratégia saúde da família: intervenção precoce para promoção da saúde. Rev Universidade Vale Rio Verde. 2015; 13(2):483-93. doi: http://dx.doi.org/10.5892/ ruvrd.v13i1.2345

18. Furtado MCC, Mello DF, Pina JC, Vicente JB, Lima PR, Rezende VD. Nurses' actions and articulations in child care in primary health care. Texto Contexto Enferm. 2017; 27(1):e0930016. doi: dx.doi.org/10.1590/0104-07072018000930016

18. Reichert APS, Rodrigues PF, Albuquerque TM, Collet N, Minayo MCS. Bond between nurses and mothers of children younger than two years: perception of nurses. Ciênc Saúde Coletiva. 2016; 21(8):2375-82. doi: https://doi. org/10.1590/1413-81232015218.07662016

20. Agbozo F, Colecraft E, Albrecht J, Timothy G. Understanding why child welfare clinic attendance and growth of children in the nutrition surveillance programme is below target: lessons learnt from a mixed methods study in Ghana. BMC Nurs. 2018; 17:25. doi: https://doi.org/10.1186/ s12912-018-0294-y 